\title{
Cooperatives Governance Structure in China: A New Analytical Framework
}

\author{
Bin $W U^{1 . a}$ \\ ${ }^{1}$ Hangzhou Dianzi University, Xiasha Higher Education Zone, Hangzhou 310018, P.R. China \\ awubin86@hdu.edu.cn
}

Keywords: Cooperatives, Governance structure, Analytical framework.

\begin{abstract}
The cooperatives governance structure has always been the research priorities in the field of cooperative economics, but so far the issue is still considered as "gray box" or even as "black box". Most of the recent researches focused on the internal governance structure of cooperatives, or take the governance structure of cooperatives as a generalized property rights. Overall, the existing researches lack of the integrated perspective, especially the targeted analytical framework. Therefore, the authors assume that the particularity of cooperatives, in a certain sense, reflected in its membership identity. On this basis, the paper constructed a theoretical analytical framework of cooperatives governance structure which could effectively explain the positioning of existing cooperative types and its evolution trends.
\end{abstract}

\section{Introduction}

The firm no longer as a production function which aims to maximize profit, but instead as a governance structure(Williamson, 2002)[1].There are many scholars agree that cooperatives are neither belongs to market structure nor bureaucracy structure, but combines the features of these two typical governance structure (Ménard, 2007[2]; Valentinov \& Fritzsch, 2007[3]; Chaddad, 2012[4]). Apparently, they have been recognized that cooperatives belong to a special hybrid form. The authors also strongly agree with this judgment.

Accordingly, in a certain sense, we can also put cooperatives as a governance structure.It can be confirmed that under the new international environment, the profound changes of cooperatives (especially agricultural cooperatives) have been have taken place both at the strategic and organizational level not only in developed countries, but also in developing countries. For instance, cooperatives in these countries the development strategies gradually from members-oriented turn to market-oriented. In recent years, the governance structure of cooperatives has always been the research priorities in the field of cooperative economics, but so far the issue is still considered as "gray box" or even as "black box". Most of the recent researches focused on the internal governance structure of cooperatives, or take the governance structure of cooperatives as a generalized property rights. Overall, the existing researches lack of the integrated perspective, especially the targeted analytical framework. Therefore, how to fill the missing is the main purpose of this research.

\section{A New Analytical Framework of Cooperatives Governance Structure}

Through a combination of the existing analytical frameworks by Chaddad and Cook(2004)[5], Nilsson (2001)[6], and Xu (2005)[7], this paper attempts to build a new analytical framework of cooperatives governance structure based on the matching degree of members' roles as investor, patron, and controller (see Fig.1). 


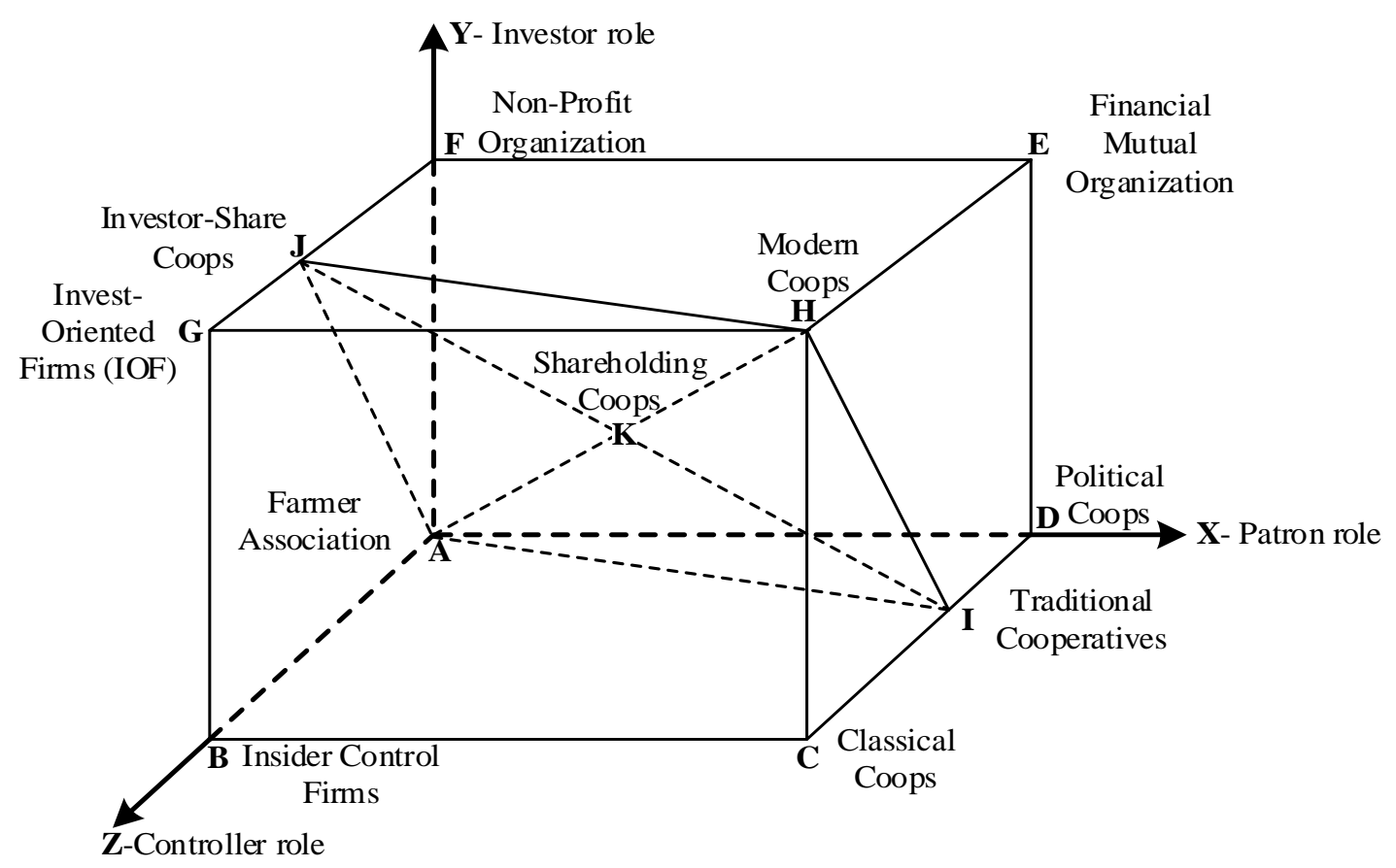

Fig.1. Analytical framework of cooperatives governance structure based on the matching degree of members' roles

\section{Explanation to the Axis of the Analytical Framework}

\section{X-axis: The Matching Degree of Members' Patron Roles}

Patrons who is the stationary users or customers. And in the narrow sense, patrons who is the users in order to obtain a part of cooperatives' net income by the way of patronage refunds based on personal business usage. Cooperatives has been able to distinguish it from other business organizations, a key sign is cooperatives requires its members not only nominally members, but also those who are actually patrons. In the Figure, X-axis characterized the matching degree of members' patron roles. Starting from the origin point (point A), the arrow direction indicates the gradually increasing of roles' matching degree. Because unlikely to exist idealized role of matching one hundred percent both in theory and reality, the intersection point with X-axis (i.e. point $\mathrm{D}$ ) is intended to represent a considerable high matching degree of roles (similar to point $\mathrm{F}$ and point $\mathrm{B}$ ).

\section{Y-axis: The Matching Degree of Members' Investor Roles (From Low to High)}

Investor refers to a person who to commit (money) in order to earn a financial return. Typically, generalized investors include shareholders, creditors and other stakeholders, and the narrowly investors means shareholders. In cooperative case, whether it is the original Rochdale principles or the modern cooperative principles which accepted by International Cooperative Alliance in 1995, throughout all contain the demands for member to commit economic participation by become a shareholder. But at the same time, due to the judgment of the nature of capital, dividend on equity capital is limited. Therefore, this "member-investors" role arrangements is an important technical operating conditions ensure the viability of the cooperatives under the competitive market environment, is a derivative role of "member-patrons". In the Figure, Y-axis characterized the matching degree of members' investor roles. Starting from the origin point (point A), the arrow direction indicates the gradually increasing of roles' matching degree.

\section{Z-axis: The Matching Degree of Members' Controller Roles (From Low to High)}

Controller refers to one that controls or has power or authority to control. For cooperatives, controller who is the users entitled to vote on important actions of cooperatives, also refers to the actual owner of cooperatives. That is, cooperatives' controller is the owner of formal decision- 
making rights. However, it must be admitted that, due to differences in personal resource endowments or the condition of "capacity and relationship (guanxi)", "one member, one vote" is difficult to achieve in reality. As an incomplete contract sets in an uncertain environment, this "member-controllers" role arrangements is an important institutional operating conditions ensure the cooperatives' purpose (i.e. to meet the demands of the interests of members).In the Figure, Zaxis characterized the matching degree of members' controller roles. Starting from the origin point (point A), the arrow direction indicates the gradually increasing of roles’ matching degree.

\section{Explanation to the Vertex of the Analytical Framework}

In the Figure, the matching degree of the three members' roles (i.e. X-axis, Y-axis, and Z-axis) constitutes a cubic structure. The actual representation of the eight vertices of the cube (i.e. point A to $\mathrm{H})$ as follows:

\section{Point A: Farmer Association}

On this point, the matching degree of members' patron, investor, and controller roles were the lowest. This paper argues that this origin point should be indicates the "Farmer Association". Farmer Association is a quasi-cooperative, focused on coordinate members' actions and supply basic production services. In China, we used to call it "Farmer Specialized Association". But in the North America, it's similar to the "Bargaining Cooperatives" in the early years.

\section{Point B: Insider Control Firms}

On this point, members do not have the investor rolesand patron roles, but only matching controller roles. This paper argues that this point should be indicates the "Insider Control Firms". The concept of "insider control" was first proposed by Aoki(1994)[8]. The original meaning of insider control is the majority stake was held by the enterprise insider (especially the manager, director and other management staff) in the process of privatization of state-owned enterprises.

\section{Point C: Classical Cooperatives}

On this point, members do not have the investor roles, but highly matching the patron rolesand controller roles. This paper argues that this point should be indicates the "Classical Cooperatives" in which members completely homogeneous and equal shareholding, voluntary access, one person one vote, and fully in accordance withpatronage refunds to distributed the net income. Patrons to return the surplus amount.

\section{Point D: Political Cooperatives}

On this point, members do not have the investor rolesand controller roles, but only matching patron roles. This paper argues that this point should be indicates the "Political Cooperatives". "Political Cooperatives" is a new concept proposed by this paper, which means the (nominal) cooperatives initiated in the form of political movements and the mass movement use of government ordinance, in the process of socialist transformation in socialist countries based on Leninist. Those cooperatives inevitably end to inefficient and even ineffective collective economic forms.

\section{Point E: Financial Mutual Organization}

On this point, members do not have the controller roles, but highly matching patron roles and investor roles. This paper argues that this point should be indicates the "Financial Mutual Organization” or "Mutual Financial Organization”.Strictly speaking,Financial Mutual Organization should be consumer cooperatives, itsmembers are policyholders, or depositors.

\section{Point F: Non-Profit Organization}

On this point, membersdo not have the patron rolesand controller roles, but only matching investor roles. This paper argues that this point should be indicates the "Non-Profit Organization(NPO)". NPO not can't engage in profit-making activities, but even if there is a surplus, nor shall be allocated to members. Therefore, by definition, NPO do not have any owner or controller. 


\section{Point G: Investor-Oriented Firms (IOF)}

On this point, members do not have the patron roles, but highly matching investor roles and controller roles. This paper argues that this point should be indicates the "Investor-Oriented Firms (IOF)". Klein et al. (1978)[9] indicates that the owner of the firms (i.e. the remaining controller) is generally the main investor. However, by Hansmann (1996)[10], these traditional enterprises controlled by the investor, just a kind of special form of producer cooperatives, more precisely, enterprise is actually Lenders' Cooperatives or Capital Cooperatives.

\section{Point H: Modern Cooperatives}

On this point, the matching degree of members' patron, investor, and controller roles were the highest. This paper argues that this origin point should be indicates the "Modern Cooperatives". Modern Cooperatives often sought to challenge the basic principles, such as open membership and decentralized decision-making rights of traditional cooperatives. They position themselves as the core enterprises of supply chain, and whom to change some of the traditional cooperatives' philosophy and operational mechanism. At present, the common Modern Cooperatives are New Generation Cooperatives (NGC) and Limited Cooperative Association (LCA).

\section{Explanation to the Oblique Surface of the Analytical Framework}

In this new analytical framework (Fig.1), this paper gives a realistic cooperative governance structure oblique surface (AIHJ). There are atotal of five marked point in the oblique surface, except point A (Farmer Association) and point H (Modern Cooperatives)already mentioned above, the remaining marked point includes:

\section{Point I: Traditional Cooperatives}

On this point, members basically do not have the investor roles, but highly matching the patron roles and matching a certain degree of controller roles. This paper argues that this point should be indicates the "Traditional Cooperatives". Different from the Classical Cooperatives (point C), Traditional Cooperatives' members can only substantially homogeneous. Though they have an equal right to nominal control based on the principle of one person one vote, generally, their acatual control rights subject to a certain extent weakening.

\section{Point J: Investor-Share Cooperatives}

On this point, members basically do not have the patron roles, but highly matching the investor roles and matching a certain degree of controller roles. This paper argues that this point should be indicates the "Investor-Share Cooperatives". According to Chaddad and Cook (2004)[5], InvestorShare Cooperativesacquires nonmember equity capital without converting to an IOF. Contrasting to the Cooperatives with Capital Seeking Cooperatives, this cooperative model issues separate classes of equity shares in addition to the traditional cooperative ownership rights held by member-patrons.

\section{Point K: Shareholding Cooperatives}

On this point, the matching degree of members' patron, investor, and controller roles were the moderate status.This paper argues that this point should be indicates the "Shareholding Cooperatives".Shareholding Cooperatives mainly refers to a new cooperative form which combined shareholding system and cooperative system. It should be recognized, Shareholding Cooperatives is more common in China (especially in the eastern coastal areas). Its organizational characteristics have considerable Chinese context features.Those Cooperatives often initiated by a number of nonagricultural production subject, not deliberately restrict members heterogeneity and "several dominant shareholder”, and presence significant demutualization trend.

\section{Conclusions and Implications}

Fundamentally speaking, the particularity of cooperative governance structure is the identity of membership, that is, a member not only as the patron, but also the investor, and still the owner 
(controller). Therefore, this paper take cooperatives as a benchmark and proving the eleven kinds of appropriate forms of economic organization based on the analysis of three member roles' matching degree. Then focuses on the five common types of cooperatives governance structure, and proposed fourteen kinds of possible evolutionary path of cooperatives governance structure.

As Bonus (1986)[11] puts it, cooperatives "characterized by a precarious equilibrium between 'centripetal' forces (benefits of collective organization), and 'centrifugal' forces (benefits of independent operation)." That is, this particular governance structure of cooperatives whose non-steadystate is the norm. This is not only because cooperatives belongingto the intermediate state of "market - hierarchy" sequence spectrum of governance structure, and with the cooperative itself is inherently dual nature (both a community and a business enterprise) are inseparable. Among them, cooperatives' ideals and purport more inclined to its community attribute, however, cooperatives'ways and meansmore inclined to its enterprise attribute. In fact, there is always an overt or covert mainline, namely, cooperatives almost inevitably towards one-dimensional development and become more demutualization in the 170 years cooperative movement in the world. However, although the cooperatives governance structure increasingly showing entrepreneurial trend, its community attribute may fade, but will not disappear.

\section{Acknowledgement}

This research was financially supported by the Soft Science Research Project of Zhejiang Province (2016C35019) and the National Natural Science Foundation of China (71373063).

\section{References}

[1] O.E.Williamson, The Theory of the Firm as Governance Structure: From Choice to Contract, Journal of Economic Perspectives, 16 (2002) 171-195.

[2] C.Ménard, Cooperatives: Hierarchies Or Hybrids? in K. Karantininis, J. Nilsson, (Eds.), Vertical Markets and Cooperative Hierarchies, Springer, Dordrecht, 2007, pp.1-17.

[3] V. Valentinov, J. Fritzsch, Are Cooperatives Hybrid Organizations? An Alternative Viewpoint, Journal of Rural Cooperation, 35 (2007) 141-155.

[4] F.R. Chaddad,Advancing the Theory of the Cooperative Organization: The Cooperative as a True Hybrid, Annals of Public and Cooperative Economics, 83 (2012) 445-461.

[5] F.R. Chaddad, M.L. Cook, Understanding New Cooperative Models: An Ownership-Control Rights Typology, Applied Economic Perspectives and Policy, 26 (2004) 348-360.

[6] J. Nilsson, Organisational Principles for Co-operative Firms. Scandinavian journal of management, 17 (2001) 329-356.

[7] X.C. Xu, Institutional Analysis on Farmer Specialized Cooperative Economic Organizations in China. Economic Science Press, Beijing, 2005. (In Chinese)

[8] M. Aoki, Control of the Insider-Control: Issues of Corporate Governance Structure under the Transitional Economy. Reform, 6 (1994) 11-24. (In Chinese)

[9] B.Klein, R.G.Crawford, A.A.Alchian, Vertical Integration, Appropriable Rents, and the Competitive Contracting Process, Journal of Law and Economics, 21 (1978) 297-326.

[10]H. Hansmann, The Ownership of Enterprise. The Belknap Press, Cambridge, 1996.

[11]H. Bonus, The Cooperative Association as a Business Enterprise: A Study in the Economics of Transactions. Journal of Institutional and Theoretical Economics, 142 (1986) 310-339. 